\title{
INIMIGO RUMOR, CABRAL, CARLITO: IMPRESSÕES ANACRÔNICAS
}

George Luiz França

Si ya ha sucedido todo, nada vale la pena.

(Paolo Virno)

\author{
Por afrontamento do desejo \\ insisto na maldade de escrever. \\ Mas não sei se a deusa sobe à superfície \\ ou apenas me castiga com seus uivos. \\ Da amurada deste barco \\ quero tanto os seios da sereia.
}

(Ana Cristina César)

Poesia... são as Moscas na boquinha grenat da Bela Bilheteira Dorotéia Adormecida no Guichet...é a Voz Sepulchral do Busto do Comendador Molina... é o Gorgolejar na Gruta da

Garganta... são as Gralhas.

(Zuca Sardan)

Tornou-se moeda corrente, na mais contígua contemporaneidade, falar em crise. No caso particular da literatura, fala-se da exaustão da idéia de vanguarda, da falta de uma produção que seja "linha de frente", da inexistência de uma poesia que não se restrinja a repetir o passado ou a "fazer volteios" cada vez mais distantes do grande público, esse fetiche. Não é desusado lembrar que poetas hoje tidos como grandes até no senso comum, como Manuel Bandeira, chegaram à Academia Brasileira de Letras sem que houvesse uma grande tiragem de seus livros; o reconhecimento, em geral, vem a posteriori. Há exceções, entretanto: Silviano Santiago, em Carlos Drummond de Andrade, frisa mais de uma vez a palavra "sucesso" ao tratar do poeta modernista, em 1976. Entretanto, esse mesmo discurso da crise também não parece ser algo tão recente quanto se possa pensar, ou seja, não é somente fruto do fim da chamada "poesia marginal" e da exaustão da febre neovanguardista concreta, esta última tão combatida e taxada de esteticista por uma crítica como lumna Simon, em textos como Esteticismo e participação (1990, p.120-140) ou Poesia ruim, sociedade pior, este último em parceria com Vinicius Dantas (1985, p. 48-60). Nesses textos, lumna procura (e raramente encontra) pontos em que a poesia contemporânea consiga fugir dos imperativos do (de algum) mercado (a que, de alguma forma, quiçá a geração marginal estivesse atendendo para cobrir $O$ preço da passagem) ou do ascetismo acrítico em que se embeberia nossa "vanguarda construtiva". Não 
discutirei, aqui, com delongas, a questão do engajamento do artista e do intelectual em termos adornianos ou lukácsianos, uma vez que nem pretendo ver a pesquisa formal como elemento fundamental a ser desenvolvido para que a arte tome lugar combativo na sociedade e duvide do desenvolvimentismo, nem pretendo tratar da necessidade da abordagem de temas engajados em formas tradicionais e acessíveis para levar as massas à revolução.

Gostaria de remeter a outro momento do discurso de crise, para chegar à cena contemporânea e à proliferação de revistas de (alguma) poesia e seus impasses. O tempo de que falo é o da dita "revisão" do primeiro modernismo, ou seja, os vínculos políticos e teóricos que fizeram com que a vanguarda acabasse por se tornar instituição. Essa crise debate-se com o surgimento de uma obra como a de João Cabral de Melo Neto, autoproclamada anti-lírica. Quando, por exemplo, Sérgio Milliet coleta seus Dados para uma [a] história da poesia moderna[ista] e os publica, primeiramente, em cinco partes na revista Anhembi, para depois transformá-los em um Panorama da moderna poesia brasileira (editado sob auspício do Ministério da Educação e Cultura), entre 1950 e 1951, encontra-se ele, também (crítico modernista paradigmático que é, como o seria Simon depois, salvaguardadas as diferenças entre ambos, dada a visão marcadamente adorniana desta), diante de um diagnóstico e de um impasse:

\footnotetext{
Vejo como característica do novo estado de espírito o temor ao pieguismo, o receio da vulgaridade, a procura de uma forma densa e limpa, com poucas imagens, mas requintadas, e que se realiza através de um jogo sintáxico rebuscado. Se alguns ainda conservam o humour é pelo que ele tem de negativo e arisco. A piada foi entretanto inteiramente abolida. $E$ se não se voltou por completo à métrica, já se tenta uma constante rítmica que se aproxima um pouco das medidas clássicas. Quanto à rima só raramente aparece, desconfiando os jovens de seus efeitos fáceis. (MILLIET, 1951, p.323)
}

O espólio da revolução promovida pela vanguarda nas formas da poesia então era casado com a tradição. A própria postura de um participante da vanguarda de comentar com desapreço o que a sua geração de poetas fez e elogiar o retorno de algumas formas como espécie de inovação soa curiosa, ou nem tanto, dado que o próprio Mário de Andrade, por exemplo, estava escrevendo sonetos antes disso, além, é claro, de fazer a célebre conferência 
de revisão intitulada O movimento modernista, em 1942. E o poeta-crítico prossegue, historiando meio século, deixando, entretanto, uma impressão, de certa forma, de déjà $v u$, como se pudéssemos pensar, talvez, que ele fala à nossa cena: de uma poesia sem mensagem (o que não é necessariamente negativo) escrita num tempo insolúvel. Um tempo que, não de hoje, é um impasse a ser resolvido até mesmo em termos teóricos. Vejamos Milliet:

O êxito dos excessos de 22 justifica-se pelo cansaço em que andávamos todos da medida parnasiana, prudente e vazia. A reação atual explica-se pelo cansaço inverso. Estamos fartos de trocadilhos, de paradoxos, de imagens milionárias, de surprêsas de tôda sorte. E, sobretudo, estamos fartos dos embustes que essa anarquia erigida em lei tem permitido. Daí a volta à forma, à disciplina, ao cuidado estilístico. Nada mais natural e nada mais benéfico. Uma nuvem apenas no horizonte; a possibilidade da forma vir a tornar-se a própria finalidade da poesia. Onde eu vejo um possível naufrágio dos revoltados de hoje é nesse recife da forma pela forma. Que o meio não se transforme em fim, que o poeta não esqueça, na sua preocupação de como dizer melhor, o que tem a dizer. E temo tanto mais que isso aconteça quanto dia a dia mais o que vale dizer se vai fazendo subversivo. [...] Por isso o diz de modo tão esotérico, de maneira a ser entendido apenas pelos espíritos anti-diluvianos, os últimos artistas que se vão enterrando sob os gelos da nova civilização e que um arqueólogo descobrirá num futuro remoto, depois da bomba atômica.

Esse amor apaixonado à forma assemelha-se profundamente a uma solução pela evasão. É o que hão de censurar aos jovens poetas de nosso tempo os que vieram de ontem com a ilusão de uma influência participante na sua bagagem literária, na sua 'mensagem'. Se a nova poesia não se apega à mensagem, ela revela entretanto uma situação. Ela assinala, como já o disse a propósito de Cabral de Mello Neto, a amargura dos tempos e a insolubilidade do poeta no clima de nossa época. E isso é positivamente grave: para o poeta, para a poesia e para a época. (MILLIET, 1951, p.323-324)

É interessante pensar que essas notas são prévias à própria aparição do Concretismo na poesia brasileira, que se daria ao longo da década de 50 e teria forte espaço de divulgação nas revistas Noigandres (que foi fundada em 1952 e publicou, em 1958, o Plano-piloto para a poesia concreta) e Invenção (1961-1967), ganhando muito pouca ou nenhuma ênfase em Anhembi. Se aparece a arte "concretista", isso se dá em termos de artes plásticas; o poema, por um lado, se mantém império da letra; por outro, continua lido na reivindicação do lirismo. Entretanto, um dos impasses que chegaria aos dias atuais (refuto o termo contemporaneidade por pensar que cada um faz seus 
contemporâneos) já está aí dado e assinalado: a crise desse lirismo. Chegarse-ia, depois, a pregar o fim do verso, idéia que, pelo que indicam os periódicos de poesia da última década, foi abandonada pela maior parte dos poetas, restando poucos que ainda nela insistem (ou dela não saíram, ou não resolveram esta outra "crise"). Mas como poderíamos desenvolver o reflexo contemporâneo dessa "pedra no meio do caminho" com que Milliet se depara ao ler João Cabral? $\mathrm{E}$ em que pode nos ser pertinente revisitá-la nesse momento? Talvez pelo fato de que um dos mais aclamados poetas dos últimos anos, Carlito Azevedo, não só ao longo de sua obra, mas na elaboração da revista que dirige desde 1997, Inimigo Rumor, renda incessante tributo ao poeta-diplomata. Borges (2008) bem nota que cada homem constrói seus precursores, na breve porém aguda leitura que faz de Kafka no texto Kafka y sus precursores, contido em Otras inquisiciones. Não seria possível armar uma rede de escritores que se ocuparam de problemas "kafkianos" se não fosse pela existência de Kafka; outrossim, é possível armar anacronicamente, também, uma rede de precursores para Inimigo Rumor. Essa rede é construída porque a revista existe, e, antes disso, porque existe um poeta que a edita. Talvez, a exemplo dos precursores que Borges encontra para Kafka, todos os membros dessa rede, de alguma maneira, pareçam Carlito Azevedo (ou Carlito pareça todos eles), mas nem todos se pareçam entre si. Essa rede poderia contemplar, dentro de uma cena multifacetada, de crise de unidade e identidade e da idéia tão propalada por Milliet de uma mensagem poética, tanto alguma(s) herança(s) concreta(s), quanto João Cabral (que, veremos, também insistia na idéia da "mensagem"), ou ainda alguns herdeiros do que foi a geração marginal, a exemplo de Cacaso, como quiçá até alguma linhagem neobarroca, de que se poderia falar a partir do nome do periódico que edita, retirado de um volume de poemas do cubano José Lezama Lima, datado de 1941. Ou, para encontrarmos ainda outros precursores (quiçá contemporâneos) de Carlito, tenhamos que voltar a Drummond, a Mallarmé, a Baudelaire.

Muito se tem falado, atualmente, da maneira como a poesia e a crítica literárias se tornaram uma espécie de campo iniciático, fechado nos círculos universitários e dos literatos, distanciando-se do público, não necessariamente 
(ou somente) pelos volteios formais, mas por uma linguagem hermética, cheia de incompletudes, imagética. Entretanto, se remetermos ao campo das revistas literárias, que, a partir do final da década de 90 do século $X X$ e na primeira década do século XXI, sofreram uma espécie de boom insondado na chamada "década perdida" dos 80, como ressalta Maria Lucia de Barros Camargo, podemos dividi-lo (ainda que haja ressalvas e especificidades) em tendências que se aproximam das revistas Inimigo Rumor, por um lado, e Azougue, por outro. Este último volta-se bastante a fazer circular uma produção que poderia ser posta na linha que vem do surrealismo e desemboca na geração beat americana. Essas "linhagens", todavia, se têm lugar no grupo de revistas que sai de Inimigo Rumor e vai gerar Monturo, Cacto e Sibila, entre outras, encontram-no de maneira muito esporádica, restrita, que perde, de longe, para a linha já apontada das outras preferências poéticas de Carlito Azevedo.

\section{Cabral, por Milliet e ao revés}

Vimos que Sérgio Milliet encerra seu ensaio sobre a poesia da primeira metade do século (que de início se propunha a tratar apenas do período entre 1922 e 1928) tratando de Cabral como um "poeta da crise". Entretanto, cabe sondar o que, anteriormente, o modernista institucional viu no poeta-diplomata para considerá-lo parte de uma crise que então atingia os jovens poetas. Ora, Cabral publica Pedra do sono, seu primeiro livro de poemas, em 1942, e, tendo apenas 30 anos quando Milliet escreve essas considerações, pode ser considerado, então, um jovem poeta. Sua busca seria, desde $O$ engenheiro (de 1945, o qual toma por epígrafe uma citação do arquiteto funcionalista Le Corbusier, dando conta da já repisada relação entre a poesia de João Cabral e alguma "engenharia poética", lida na maioria das vezes como anti-lírica, mas que preferiria chamar de dotada de algum lirismo sui generis), marcada por "pureza geométrica dos volumes, a limpidez funcional e a criação livre. E através dessa forma sem concessões, a comunicabilidade emotiva. Nada mais nada menos do que a grande poesia, portanto..." (MILLIET, 1951, p.70) Ora, Milliet tenta encontrar, em João Cabral, primeiramente reativando uma espécie de ut pictura poiesis, de cunho horaciano, a comunicação de que justamente a 
poética daquele parece fugir. As imagens que Cabral cria em seus poemas talvez pudessem ser aproximadas, mais efetivamente, do punctum que Barthes (1984) desenvolve em A câmara clara ao tratar da fotografia: não se dão por inteiro, mas têm um potencial de laceração, de pungência, derivado justamente daquilo que não comunicam, mas do diferimento com que nos chegam. Talvez seja esta uma leitura válida não para o que Milliet pensa de Cabral, mas sim para o que alguém como o tradutor de $A$ câmara clara para o português, Júlio Castañon Guimarães, co-editor dos primeiros números de Inimigo Rumor poderia ali ler.

Em seguida, Milliet direciona sua análise para o paralelo entre as ambições cabralinas e as daqueles já entendidos como mestres: Valéry e Mallarmé, que souberam acumular "reservas de emoções para tirar delas uma essência forte, capaz de resistir à diluição de todas as interpretações." (ibid., p.70) O poeta figura, então, como o depurador de emoções, como aquele que busca a melhor forma, a mais "consistente e densa" para construir um efeito, o qual não poderia, entretanto, recair nos "simples jogos abstratos, sutilíssimos sem dúvida, e até sedutores, mas falazes." (id.) A esses jogos Milliet chama "intelectualismo", coisa que faz a "comunicabilidade" cessar. É, talvez, um grande impasse a ser considerado: deve a poesia comunicar? Há alguma possibilidade de comunicação para a linguagem? Ou o que se deve procurar na linguagem, na poesia, é o ponto em que a linguagem trabalha contra si mesma, o tempo em que ela implode o constructo da comunicação, gozando com o rumor da língua?

Mas há um ou dois comentários de Milliet que parece amarrar essas duas poéticas separadas no tempo que aqui tentamos ligar: a de Cabral e a de Carlito. Primeiramente, o crítico diz que um traço "cesaniano" caracteriza Dantas Mota, a quem faltaria um pouco de desenho (de "serviço militar do cubismo"), que daria a sobriedade adquirida em Elegia do País das gerais. Esse mesmo traço é mapeado em João Cabral de Melo Neto. Seria o caminho da desejada "sobriedade" o aprender a definir as formas? Não é desusado lembrar que é em Cézanne que Davi Arrigucci Jr. busca um caminho interpretativo para o poema $A$ maçã, de Manuel Bandeira. Mas estaria isso também em Carlito Azevedo, cujo poema mais conhecido talvez seja As 
banhistas, justamente uma espécie de leitura de uma tradição de telas em que se poderia encontrar, entre tantos pintores, Cézanne ${ }^{1}$. Não seria esse mesmo caminho algo que se poderia aproximar da lira, cuja etimologia é remontada por Agamben (2002) em O fim do poema ao traço do arado, firme e reto, a que se contraporia o de-lírio, o fugir da linha, da razão? O que se percebe, entretanto, na leitura de Carlito, é que essa plasticidade não é obtida através dos efeitos visuais tão propalados pelo Concretismo em seus decretos do fim do verso. Carlito versifica, e o faz muito bem, como João Cabral o fazia. Sua maneira de criar imagem em poesia não representa uma ruptura com toda a tradição lírica versificadora, nem um investimento em um decreto tão datado que foi abandonado até mesmo por Haroldo de Campos (veja-se, a propósito, Renga em New York, poema que abre a Inimigo Rumor de número 1).

Encontramos uma espécie de plástica tanto na obra de Cabral quanto na de Carlito, muito menos empenhadas que são em mergulhos em um sujeito definido, dado a priori, mas na construção de momentos de subjetividade a partir de cenas em que as imagens fixadas denunciam a existência de um olhar, e neste, de um corte, e neste corte, de uma linguagem, concomitantemente à qual se dá a armação do sujeito. Entretanto, apenas pela perceptível armação racional que há nelas podemos dizer que se trata de geometria poética? Ou haveria o que pudesse escapar do esquadro, o momento em que a razão própria se perde em si dentro dessas poéticas? Diria Milliet: "O poeta não quer ser dominado pela inspiração. Quer controlá-la. Êle se recusa às palavras em liberdade, aos clarões do inconsciente. Tudo passará por um crivo selecionador e se transformará em geometria." (MILLIET, 1951, p.73) Creio que o ponto de relação entre poesia e imagem, bem como entre trabalho poético e tradição, seja um ponto para se abrir uma leitura anacrônica de Cabral e Carlito. Entretanto, cabe uma explanação sobre essa idéia de uma teoria do tempo que nos permite ver a diferença na repetição (para dizê-lo em termos deleuzeanos), ou ainda, desmistificar a idéia de que o mundo pós-

\footnotetext{
${ }^{1}$ Não me deterei, neste momento, numa análise mais aprofundada dos paralelos entre a pintura e a poesia, A esse respeito, ver AGUIAR, Melânia Silva de; LOBO, Suely M. P. e Silva. Ler um poema: poesia e pintura em Carlito Azevedo. Disponível em: $<$ http://www.ich.pucminas.br/posletras/Producao\%20docente/Melania/Carlito $\% 20$ Azevedo\%20texto\%20leitura\%20-\%20Suely\%20-\%20Melania.pdf>. Acesso em 14 jan. 2008.
} 
moderno é apenas déjà $v u$, para depois, no embate corporal com alguns poemas de ambos, pensar como Carlito se torna o armador de um arquivo póscabralino de poesia, sobre o qual, talvez, se possa dizer que siga o exemplo de Eliot (em Tradição e talento individual, aqui utilizado em edição não datada, mas inicialmente publicado em 1919), para quem o bom artista seria aquele que sabe encontrar o seu lugar dentro da tradição, e não denegá-la, a exemplo do que as vanguardas fizeram. Entretanto, mesmo as vanguardas acabaram por construir seus paideumas, suas outras "tradições válidas": resta lembrar, por exemplo, da importância do barroco mineiro para a produção modernista, ou ainda, das revisões de Sousândrade e Kilkerry ou dos empréstimos de Pound feitos pela neovanguarda concreta. Por fim, caberia uma contraponto entre essa inscrição de Carlito e o discurso do im(pós)sibilismo de Sibila, que, apesar de fazer um investimento em inovação, ainda se relaciona com o passado a começar por seu nome, arrancado a um poema de Murilo Mendes. Bem, vale lembrar que o nome Noigandres também é arrancado à tradição, mas não à brasileira: saiu de um poema de Ezra Pound.

\section{Poéticas do anacronismo}

Pensar essas correspondências sem uma teoria do tempo que nos permita sair de uma concepção linear, evolutiva e homogênea dos fenômenos seria impossível. Em nenhum momento postulo que Carlito Azevedo seja a evolução de Cabral, combinada à herança do Concretismo e da poesia marginal: seria ingenuidade. Carlito visita esse arquivo e lida com ele com liberdade, construindo uma poética atual porque anacrônica formal. Emprego, aqui, as idéias de Paolo Virno em Recuerdo del presente, que tem por subtítulo Ensayo sobre el tiempo histórico. Vejamos, pois, em que termos se desenvolve a teoria de um anacronismo formal e como e por que se pode dizer isso da poesia de Carlito Azevedo.

Virno começa por considerar que há, sim, um significado suprapessoal para os fenômenos da memória, mas denega a existência de uma memória histórica coletiva, preferindo considerar que, em relação à história, haja conhecimento ou cultura. A memória seria a "facultad que distingue la 
existencia singular." (VIRNO, 2003, p.12) Entretanto, essa mesma faculdade, que seria a recapitulação ontogenética dos modos de ser histórico, participa de um fenômeno característico da percepção pós-moderna, e que se caracteriza, ao ver de Virno, como patologia: o déjà vu. Este seria não como repetição efetiva do passado no presente, mas um acontecimento que se dá na ordem da percepção, ou seja, o indivíduo considera haver repetição efetiva do passado no presente quando, em verdade, está diante de uma ilusão, de um falso reconhecimento. "Se cree reconocer algo que, por el contrario, recién se conoce ahora. Es por ello que, refiriéndose al dejà vu, se habla también de 'falso reconocimiento." (ibid., p.13) Trazendo esse pensamento para o plano da crítica e da produção literárias, podemos seguramente falar sobre a sensação de falta de novidade de alguns críticos, produzida, principalmente, pela exaustão dos projetos vanguardistas e pela auto-referencialidade recorrente na literatura, esse ser em crise. "Nada de novo no front", parecem dizer alguns críticos. Ao que se poderia arriscar uma resposta: a novidade é o trabalho com o arquivo, é produzir a diferença a partir da disponibilidade da tradição. Entretanto, esse fenômeno não é considerado pelo filósofo como uma anomalia ou uma alteração da memória, mas sim como uma ampliação de sua potência e de seus domínios. A memória, facilmente associada à idéia de passado, estende tentáculos para o presente, que, por sua vez, toma a forma de passado. Daí viria, pois, o estado de apatia, de indiferença que geraria a posição do contemplar-se viver: o sujeito se tornaria espectador de suas próprias ações. Contudo, pensando no caso da ampliação recente da produção de poesia e de periódicos a ela dedicados, creio que valeria dizer que, deixando de lado considerações sobre a maior ou menor qualidade deste ou daquele poeta ou "grupo" (se é que há algum), a apatia é vencida pelo desejo de produzir, de publicar, pelo ímpeto que mantém viva a poesia, ainda que em crise e para público restrito (e algum dia foi ele grande?), quer sob discursos ainda investidos da idéia de novo, quer sob a idéia de que "apesar de tudo, se faz", ou ainda, de que a idéia de novo é caso superado e que cabem os diferentes modos de relação com o arquivo, com a linguagem. Outrossim, essa experiência da apatia talvez esteja ligada à experiência da exaustão, ao abandono do cansaço modernista pelo contato com os abismos, com a 
abjeção, com uma experiência do limiar, do estar ao ponto de perecer, da máscara mortuária, do toque do morto, da imagem.

Bergson, retomado por Virno, fazia a distinção entre dois modos de existência: o atual e o virtual. O italiano desdobra essas considerações da seguinte forma:

\begin{abstract}
la percepción fija el presente en cuanto real, acabado, resuelto em uinívocos datos de hecho; el recuerdo lo retiene, en cambio, en el ámbito de la simple potencialidad, lo guarda como algo virtual. La diferencia entre las dos formas con las que pretendemos tomar posesión de nuestro 'ahora' es, por lo tanto, una diferencia modal: modalidad de lo posible o modalidad de lo real, memória de la potencia o percepción del acto. (ibid., p.23)
\end{abstract}

Ou seja, teríamos, aí, duas formas de pensar uma relação do acontecimento presente com o passado: o fato em si, como algo acabado (e não nos esqueçamos que as reflexões de Nietzsche em Aurora sugerem que o fato é uma construção lingüística), e o fato potencial, ou o que o fato carrega da potência do passado em si, não pensado a partir de um ato pontual, mas sim da carga que é, de uma massa quase que indefinida, mas produtora de sentidos, recombinável. A essa potência cabe a memória; ao ato, a percepção. Cada ato toma em si a potência resultante de outros tantos atos já ensaiados: não há, em suma, o que não esteja carregado de passado. Entretanto, essa carga pode se manifestar de maneiras diversas: as formas do diferimento nessa potencial repetição nos permitem fazer a leitura do que Virno chamaria "anacronismo formal" e "anacronismo real".

Cabe adicionar, ainda, que, no exercício de uma crítica que se pretende anacrônica, travamos relações não apenas com os fatos em si, mas com tramas potenciais entre eles, com ficções, portanto. É o que se pode deduzir das reflexões de Virno quando este diz que "el ser-posible del hecho, si bien pertenece al presente, se ve como ser-sido-posible: mediante um anacronismo sistemático, pues." (ibid., p.25) O anacronismo nos faz entrar, portanto, no campo da possibilidade, da devolução de potência aos atos através de diferentes entrelaçamentos a eles imprimíveis. O mesmo se pode ler em relação à produção artística: repetir ou diferir o passado? Talvez esteja aí uma disjuntiva que permita ler algo da produção selecionada para Inimigo Rumor, o 
que será feito adiante, na seção pertinente. Lidando, pois, com o passado como potência, como campo do possível, ou seja, não como ponto, mas como massa (se podemos propor uma metáfora), o filósofo italiano propõe, avançando no que dizia Santo Agostinho, que se deveria falar em um "pasado del pasado (el antiguo 'recuerdo del presente', que se afianzó entonces en esa percepción); de un pasado del presente (tal como emerge en el fenómeno del dejà $v u$ ); de un pasado del futuro (la memoria del porvenir, instituida por el 'habré sido')." (ibid., p.31) A forma pura dessa anterioridade seria, pois, a língua, no campo do possível: a língua seria o lugar primeiro do passado-emgeral. Portanto, não há dizer que não porte em si carga de passado; e cada prática traz em si um conjunto de correspondências, mudas, mas que falam.

É importante distinguir, antes de entrar em considerações sobre a produção de Carlito em relação com os dizeres poéticos que a precedem, especialmente os do fim do século XIX e de todo o século $X X$, dois tipos de anacronismo produzidos justamente em função da diferença entre a memória do presente e o falso reconhecimento. Para Virno, a memória do presente (a presença da massa do passado no momento atual) distingue-se do falso reconhecimento por provocar a experiência do possível, ao passo que o falso reconhecimento a dissimula e a bloqueia.

\footnotetext{
El presente recordado es virtual: potencia que coexiste con el acto (percibido), sin anularse. En el 'falso reconocimiento', por el contrario, la vigencia simultánea de las instancias heterogéneas (potencia y acto, precisamente) se camufla de repeticiones, repartidas cronológicamente, de lo homogéneo (el acto): el 'ahora'posible es desplazado por um 'entonces'-real; el evento presente parece la réplica automática y alucinada de otro evento, consumado en un período anterior. (ibid., p.35)
}

É partindo dessa distinção que o filósofo italiano estabelece as diferenças entre os dois tipos de anacronismo de que falei ao abrir esta seção: o formal e o real. O anacronismo seria, pois, para Virno, a transposição do aqui e do agora para o passado. No caso formal, trata-se de aplicar a formapassado (a língua, a faculdade) ao presente em curso. O ato em si, no caso, proferir uma palavra, escrever um poema, passa a ser testemunho de toda a competência lingüística, diferimento de toda a tradição, de toda a linguagem. $O$ presente passaria, portanto, a poder ser considerado sob a perspectiva da 
faculdade, da potência temporalizada, da temporalidade da potência. (ibid., p.36) Dar-se-ia, assim, a concomitância, mas também o hiato, entre faculdade e ato, o que exibiria o tempo histórico, ou, num dizer benjaminiano, as camadas de poeira acumuladas por sobre a ruína que ora se tem em mãos, para retomar a metáfora arqueológica de Sobre o conceito de história. A história, para Virno, é o cruzamento entre os atos, os "agoras", e o passado "em geral", ou seja, o passado como potência, como faculdade. A experiência histórica se dá como diferimento, pois não há que se confundir o que Virno chama de "formapassado" com um fato no passado (ibid., p.38-39). Os atos presentes modificam essa forma, uma vez que, enquanto ocorrem, também se inscrevem no passado; entretanto, cada ato já feito participa da forma-passado, mas não a é. A forma-passado corresponde a um poder-dizer, a um poder-fazer, a uma faculdade em si, e não a um feito, a um dito.

Em contrapartida, quando a simultaneidade entre potência e ato é negada, bem como as diferenças entre ambos, estamos, para Virno, diante de um anacronismo real. Aqui, a repetição não se dá (ou não se lê) como um diferimento temporal, que porte em si a carga que a própria história imprime sobre o tempo, ou sobre a linguagem: trata-se de enxergar o retorno como idêntico, como exausto, como sem-potência. Toma-se, nesses casos, um ato como se fosse a potência, e, dessa forma, dado que dois atos não são concomitantes, o ato fica esvaziado da potência que lhe daria carga histórica. "El falso reconocimiento [característico de um anacronismo real] cierra el hiato entre potencia y acto que el recuerdo del presente há puesto a plena luz." (ibid., p.40) O ato, esvaziado de potência, perde-se, torna-se apenas mais um; esvazia-se, também, de seu sentido histórico.

Nesse sentido, desenvolverei, na próxima seção, um jogo de correspondências entre a poética de Carlito e a de Cabral, mostrando haver, ali, aproximações e afastamentos que podem ser lidos pelas vias de um anacronismo formal, o qual, outrossim, serve para ler parte da seleta que Carlito, como "escolhedor", faz em Inimigo Rumor. Entretanto, como as linhagens encontram-se imbricadas e a cena poética do presente ainda não nos permite desenhar um panorama claro (todo panorama é obrigado a pecar por imprecisão, sob pena de se tornar tão grande quanto o próprio território, 
outra lição tomada a Borges de Del rigor en la ciencia, parte de El hacedor), creio não haver um alinhamento entre as poéticas dos colaboradores de Inimigo. Esse descompasso, veremos, fica nítido na co-presença de Augusto e Haroldo de Campos na revista, na diferença que se imprime entre o primeiro e Zuca Sardan, ou ainda, no tributo conjunto a Sebastião Uchoa Leite, João Cabral de Melo Neto, Ferreira Gullar e Cacaso, tão diversos que são.

\section{Incisão}

Um arquivo de Carlito Azevedo montado por ele próprio talvez possa ser elucidativo, já que este tanto se eclipsa ao longo das páginas de Inimigo Rumor. Com efeito, em 19 edições da revista, o poeta colabora com 33 traduções de textos, mas apenas 13 textos de sua autoria, nem todos poemas. Se se pode dizer, com Derrida (2001, p.56), que "não haveria arquivamento sem título (e portanto sem nome e sem princípio arcôntico de legitimação, sem lei, sem critério de classificação e de hierarquização, sem ordem e sem ordem, no duplo sentido desta palavra)", que encadernar é um ato de amor (ibid., p.34) e que o arquivo é uma questão pertinente não apenas ao passado (como arqueologia), mas também ao futuro, vale visitar um arquivo em que Carlito guarda coisas que precedem e sucedem a revista que criou: sua antologia, intitulada Sublunar, a qual guarda traços para algumas reflexões em relação a João Cabral e a um possível crivo de Inimigo Rumor. Antes de mais nada, cabe mencionar que o próprio Carlito credita a organização temática (e não linearmente cronológica) de sua antologia a uma eqüidade com o que fizera Drummond, o que faz com que possamos pensar que trata aquele que foi uma das maiores fontes de João Cabral como uma tradição em que se inscrever, da qual se apropriar. Algo como (mais) um totem (sem que esse "mais" tenha cores depreciativas). Cabral é inclusive homenageado em 3 variações cabralinas, ali coligidas, as quais se centram no fogo, talvez em uma possível fulguração do poeta nessa "noite" que perpassa a poesia de Carlito.

Talvez os modos de relação com a pintura e com a visualidade sejam bons modos de se adentrar a poética de Carlito. Disse que se trata de uma poética de imagens, fundamentalmente, mas também, alicerçada em uma 
plasticidade que, como vimos, já foi tratada até pelo viés da comparação com as pinceladas e com as realizações impressionistas. Entretanto, creio que cabe mencionar mais do que isso: muito menos do que retornar a um debate que poderia ser deflagrado com Horácio e passar por Lessing, por exemplo, a respeito do ut pictura poiesis, poderíamos dizer que um dos pontos fortes de uma poética na contemporaneidade é justamente a criação de imagens, ou ainda, dizer que a poesia é imagem porque pode ser lida pelo viés do corte e da repetição (como Agamben (1995) lê o cinema de Guy Debord). Mas a citação plástica em si é explícita em muito do que escreve Carlito Azevedo. $O$ exemplo mais fácil a ser retomado nesse momento quiçá seja As banhistas, tema repisado e tributário de Cézanne, fundamentalmente, mas de outros tantos pintores que retrataram cenas de banho; entretanto, jogos de linguagem como Água forte (título tomado a uma técnica de gravura em metal feita com ácido nítrico, mas usado para retratar a trivial cena do mexer uma xícara de café, como se essa visão fosse, também, uma marca sobre o sujeito, uma queimadura, um contato). A fotografia também toma parte desse repertório plástico, a exemplo de Realismo (que menciona um "zoom de azuis") e De uma foto. A obsessão imagética de Carlito parece repercussão de Cabral, bem como o emprego da versificação (em Sublunar há apenas um poema em prosa; Inimigo Rumor chega a dedicar um número a coletar poemas em prosa de outros colaboradores, mas a predileção é clara pelo verso), e em ambos acaba direcionada ao que, primeiramente, poderia ser lido como esvaziamento do sujeito, ou seja, o canônico dizer da anti-lira impresso sobre a produção cabralina, inclusive por ele mesmo, na dedicatória de $A$ educação pela pedra a Manuel Bandeira. Entretanto, não há que se questionar que o olhar, que recorta, é uma presença de sujeito? Todas as cenas são (con)(de)(s)formadas pelo olhar de um eu lírico, ainda que este esteja eclipsado, ou não fale diretamente de si, não se enuncie como eu. A construção (para tomar uma palavra ao gosto da engenharia) da cena acaba sendo, outrossim, construção do sujeito, armação concomitante à linguagem.

Se pretendo seguir o viés da imagem, do olhar, hei de tratar do corte e da repetição. O corte é aqui lido não apenas como o enjambement, mas, de acordo com Agamben (1995; 2002), como o exercício da força que permite 
produzir hesitação entre a série sintática e a série semântica, entre a forma e o sentido, inseparáveis que são em poesia, ou, em termos derridianos, devolver à linguagem pontos críticos de indecidibilidade, combater dentro dela a evidência do sentido. Eis o rumor de Cabral e Carlito; o incessante rumor da língua, de que falava Barthes. A cena é cortada e devolvida na linguagem (e não através desta), reganhando potência, deixando de ser momento anulado na massa informe.

A repetição é um procedimento que toca Cabral e Carlito de maneiras diferentes. Basta um rápido passeio, por exemplo, por $A$ educação pela pedra para perceber que vários poemas se emparelham de forma palimpséstica, como se fossem reescrituras uns dos outros, como se apontassem para o fato de que a linguagem nunca pode dizer a cena vista, de que a cena pode sempre ser outra se o olhar for armado de maneira diferente. É o caso, por exemplo, de O mar e o canavial e O canavial e o mar, cuja estrutura se reverte, mas toma praticamente o mesmo verso como início: "O que o mar sim aprende do canavial" / "O que o mar sim ensina ao canavial" (MELO NETO, 1975, p.7;14) A anti-lira também entra em problema com a memória, que se itera em relação aos lugares; é prateleira onde cabem Recife e Sevilha: "Diversas coisas se alinham na memória / numa prateleira com o rótulo: Sevilha" (p.18); digamos que o gatilho da memória dos lugares em distância, aqui, seja deflagrado por uma estrutura que retorna sempre diferida: a imagem de Recife não é a de Sevilha. Espaço é tempo. O que se dá é um retorno, mas nunca do idêntico: o horizonte do possível é restituído; transforma-se o real em possível e o possível em real. (AGAMBEN, 1995, p.4) Essas repetições acabam por representar uma quebra na ficção do tempo como unidade linear e homogênea, e projetam um arquivo em direção ao futuro, mas não de uma maneira vanguardista. O futuro se projeta como possibilidade, não como fatalidade: o futuro é um passadofuturo, traz em seu bojo a poeira das ruínas do tempo.

Em Carlito, por sua vez, podemos observar outras repetições. Primeiramente, em termos da elaboração de seus poemas, ela se dá em títulos iguais para textos diversos, que acabam por se constituir em reescrituras doutra ordem. Carlito arquiva sob rótulos iguais em sua prateleira cenas diversas. Vers de circonstance, por exemplo, é título empregado em poemas 
que integram várias das partes de sua antologia: desde o primeiro, à página 16, retomando o tópico infantil de Drummond (e de Proust, se quisermos pensar com o Silviano Santiago de Entre Marx e Proust, publicado em 1981, emblemática leitura que faz do modernista) e uma verve rítmica tributária das cantigas de roda infantis, que prova que alguma forma da lírica ainda está presente nessa poética de assimilação em que se constitui a obra de Carlito. Vale assinalar que o nome de Proust é, ainda, citado junto com o de Octavio Paz como o de um companheiro de elaboração de Metamorfose, nome que nos poderia levar a tocar Kafka, ou ainda, na tradição clássica, Ovídio. O outro Vers de circonstance parece altamente trivial se soubermos que Carlito Azevedo é casado com uma Marília (Garcia, diretora da revista Modo de usar \& Co.), mas esse mesmo passeio com Marília pode também voltar à tradição, quiçá a Tomás Antônio Gonzaga e sua Marília de Dirceu (atamos também o elo da tradição com Ovídio, quiçá agora o das Geórgicas, ou mesmo com os ensaios a respeito do Arcadismo nas primeiras Inimigo Rumor), transportada a caminhar pela Lagoa Rodrigo de Freitas. Nesse mesmo poema, retorna a obsessão pictórica de quem fixa tantas paisagens (não raro presentes já nos títulos dos poemas) ou de quem tanto fala de fotos. Mas cabe ainda falar de duas reescrituras. A primeira delas são as duas versões de $\mathrm{Na}$ noite gris, datadas de 1991 e 1996 (p.41-42), postas uma ao lado da outra na antologia. As cenas se revertem: perde-se o fulgor, ausentam-se os tigres, o cigarro que era sol deixa apenas o breu (relampeja), as peles perdem o apelo, tudo se encaminha para a morte. A metamorfose da cena com o passar do tempo é de decadência. É como se progressivamente a noite se fechasse mais e mais; mas seria a noite o limite? Carlito nos impõe, nos insolúveis tempos em que a lírica tem de procurar sua solução no arquivo, a problemática do Limiar (p. 4041), outro de seus poemas reescritos. No primeiro deles, o limiar é um ponto de passagem; expõe, justamente, a questão do não-limite, do para-além a que a produção contemporânea sempre tem de se alçar, e pode fazê-lo, se quisermos procurar, talvez, a solução dos tempos insolúveis, através dos ditos anacronismos formais, que profanam o seguir do tempo e irrompem na cena de modo a provocar alguma reação dos sujeitos num mundo em que as imagens perderam o impacto pelo excesso. No segundo, a pedra, antes aporia no meio 
do caminho do poeta modernista, depois feita alicerce por João Cabral para uma poética (ainda com ranço pedagógico, por propor uma "educação", como proporia também o Concretismo para os sentidos) que gostaria de primar por se afastar do sujeito (mas nunca pôde abstraí-lo), é uma mancha que se acende, é luminosa e sem artifícios, desnudou-se; é, como o que julgamos ser real, uma trompe d'oeil.

Para fechar essa incisão, parênteses para leituras comuns (e cruciais) para Cabral e Carlito. Mallarmé, primeiramente. Para tomar apenas um caso isolado de relação, detenho-me no fato de que é do soneto Salut que João Cabral de Melo Neto retira a epígrafe de seu primeiro livro, Pedra do sono: "Solitude, récif, étoile..." (poema que também é mote da idéia de poema póseventural de Raúl Antelo, da qual tratarei adiante), dedicado a ninguém menos do que Carlos Drummond de Andrade. Por sua vez, a eleição de Carlito recai sobre Le bel aujourd'hui, fragmento de um verso de outro poema de Mallarmé, sem título ("Le vierge, le vivace et le bel aujourd'hui") tornado título de um poema seu (AZEVEDO, 2001, p.96). Nas duas pontas dessas tomadas de Mallarmé, uma concepção de linguagem que muito pode nos interessar para adentrar Inimigo Rumor: o rien, o nada que, diferente do néant, do não-ente, não pressupõe uma oposição dialética; e, no segundo caso, na reapropriação do "cygne" (já caro a Baudelaire, a partir de quem Carlito também escreveu sua A nova passante), um apontar para o fato de que o deslizamento do signo instaura-se dentro da própria palavra, de que a língua rumoreja a partir de dentro de si própria, de que o sentido não se dá per se, e de que a linguagem é o campo privilegiado da instauração da différance, num dizer à Derrida.

\section{O outro arquivo: Inimigo Rumor}

Já mencionei, anteriormente, que Sublunar poderia ser lida como um arquivo de Carlito, uma vez que é uma antologia, organizada de acordo com alguns princípios, pelo próprio autor. Entretanto, Carlito não arquiva apenas a si próprio: podemos considerar que vários fatos em torno da revista de que ele esteve à frente nos 20 números publicados até o presente momento, ainda que dividindo a direção com algum outro poeta brasileiro (Júlio Castañon 
Guimarães, até o número 7; Augusto Massi, do 7 ao 10) ou português (nos números em que Inimigo Rumor se tornou binacional) ou com um conselho (que reúne, intermitentemente, poetas como Marcos Siscar, Aníbal Cristobo, Paula Glenadel, entre outros), nos autorizam a pensá-la como uma outra forma de arquivo. Pensarei, primeiramente, com Derrida, a noção de arquivo, para depois ler traços da revista como arquivo e de sua(s) poéticas na contemporaneidade e no seu apontar para (algum) futuro.

Inimigo Rumor teve seu primeiro número publicado no início do ano de 1997. Em termos de aspecto gráfico, sofreu várias alterações ao longo de vinte edições em dez anos. Até o número sete, manteve-se altamente sóbria, uniforme em sua apresentação visual: uma brochura de formato pequeno, com detalhes pequenos no topo e no pé da página, o nome em letras grandes e o subtítulo "revista de poesia". Todavia, seus números não se compõem apenas de poemas: ensaios críticos de e sobre poetas, resenhas de lançamentos recentes tanto de criação como de crítica e entrevistas com nomes ligados à poesia também compõem suas páginas. No primeiro número, nada de um grande editorial de abertura com promessas para a cena poética do presente; somente uma nota prometendo que a revista seria trimestral e dedicada "preponderantemente" à poesia e que seu nome fora retirado de uma coletânea de poemas de José Lezama Lima, intitulada Enemigo rumor (1941). Essa mesma nota é publicada repetidamente até o número sete do periódico, quando desaparece. A revista dificilmente publica ilustrações ou fotos dos poetas: apenas o nome no topo da página e os textos, que querem falar por si, mais ou menos independentes de seus autores. Vez ou outra, como em textos de Cabral (n. 1) ou Ferreira Gullar (n. 3), encontramos fac-símiles de escritos.

Essa simplicidade do aspecto gráfico parece se justificar, novamente, no tributo a João Cabral, de que já falei a respeito da poesia de Carlito Azevedo. Podemos lê-la em correspondência com um dos textos de Cabral que Inimigo Rumor republica, em seu número 3. Essa edição da revista foi dedicada a Ferreira Gullar e eis que, entre uma reunião feita por Carlito Azevedo com poemas esparsos de Gullar, poemas a ele dedicados e um ensaio crítico sobre o problema do tempo em sua poética, assinado por Leonardo Martinelli (bastante jovem se comparado à média de idade dos 
colaboradores da revista), irrompe um texto datado de 1954, publicado no jornal A Vanguarda. Ali, João Cabral de Melo Neto (in INIMIGO RUMOR, n. 3, set.-dez. 1997, p.37) traça amplos elogios à maneira como Ferreira Gullar utilizava a "arte tipográfica", a qual denotaria "uma compreensão correta do livro, não como objeto de adorno ou mostruário de requintes gráficos, mas como meio de transmissão de determinada mensagem, tanto mais realizado quanto mais perfeitamente ajustar-se a seu texto e contribuir para sua completa apreensão." O papel não deve ser, para João Cabral, simples depósito de poema: a lição mallarmaica a respeito do branco da página como elemento significante é apreendida e cobrada. Entretanto, por outra via, Mallarmé também foi reivindicado pelos concretos, que inclusive o traduziram. Mas a relação de Inimigo Rumor com os concretos é dúplice: os publica, mas jamais poderia se chamada de uma revista neoconcretista. O drama do fim do verso parece vencido, ainda que haja espaço para o poema em prosa e mesmo para os experimentos (se ainda se pode chamá-los assim) visuais de Augusto de Campos, Arnaldo Antunes e para um caso à parte destes, que é Zuca Sardan.

Acontece que a revista, a partir de seu oitavo número, começou a mudar seus layouts; entretanto, a alteração fundamental se deu apenas na capa, que passou, nos números 8 e 9 , por um período um tanto quanto poluído visualmente, cheio de anúncios dos poetas publicados, ficou mais sóbria no 10 , quando publicou apenas seu nome e uma foto assinada por Ana Paula Albé na capa e, por fim, caminhou para um formato ainda mais próximo de um livro, até mesmo com capa dura cujos designs brincavam com as palavras Inimigo Rumor ou suas iniciais. O verso das edições até o número 7 contém apenas os nomes dos colaboradores. Nos números 8 e 9, surgem poemas de Francisco Alvim e Paulo Henriques Britto, respectivamente. O 10 torna a trazer as firmas dos autores, separadas, desta vez, por tipos de colaboração, diferentemente dos primeiros números, em que faziam seqüência indistinta. Intermitentemente, essas indicações somem e reaparecem nos números posteriores ao 10.

Disse que não há um editorial no primeiro número de Inimigo Rumor. Contudo, Maria Lucia de Barros Camargo (1999) aponta para mais um fato envolvendo João Cabral de Melo Neto, Carlito Azevedo e a revista que este dirige: a publicação, no primeiro número desta, de uma carta de Cabral a 
Clarice Lispector, na qual o poeta menciona seu desejo de criar uma revista chamada Antologia e convida Clarice a ser uma "escolhedora" de textos. Além de comentários sobre a impressão, dado que João Cabral começara a se aventurar pelas atividades tipográficas e queria imprimir um livro de Clarice e outro de Bandeira, ou sobre outra espécie de "impressão", aquela marca do contato de corpos sobre a qual tanto falara Derrida, ressalta o que seria o programa de uma revista que pode ter muito paralelo com Inimigo Rumor:

\begin{abstract}
Será uma revista minoritária, de 200 exemplares, distribuída a pessoas escolhidas pelos editores. Não terá programa formulado, não dará nenhuma bola à chamada vida literária, não terá seções, nem de cinema, nem de livros, nem de nada. Qualquer coisa fora do tempo e do espaço - um pouco como nós vivemos. O fim verdadeiro da revista será o de começar a escolher o que presta de todos nós. Qualquer coisa como um balanço de antes do fim de ano, um balanço dos fevereiros que nós todos somos. (INIMIGO RUMOR, $\mathrm{n}$. 1, p.30)
\end{abstract}

A pesquisadora compara o procedimento de usar uma carta de poeta consagrado ao que fizera a revista José, quando publicara uma carta de Drummond a Mário de Andrade, em seu número 9, de 1978, esperando um boom de vendas que, contudo, não aconteceu. No caso de Inimigo Rumor, o motivo parece diferente. É como se uma revista literária do final do século $X X$ assumisse a não-efetivada missão do poeta estreante dos anos 40. Entretanto, há que se ver com ressalvas esse balanço (com dístico tributado a Valéry: plus élire que lire) que teoricamente Carlito estaria se propondo a fazer com sua revista. Primeiramente, porque nem só de poetas com uma obra já em ponto de ser pesada se faz Inimigo Rumor: Leonardo Martinelli e outros estreantes estão na revista, em um espaço que também publica desde traduções de poetas gregos antigos a franceses modernos dos mais consagrados, como Valéry, Saint-John Perse e outros, como também nomes que se consolidaram em linhagens absolutamente diferentes da poesia brasileira do século $X X$. A co-presença de Haroldo e Augusto de Campos na mesma revista que Ferreira Gullar (antigo desafeto dos irmãos concretistas) e poetas ligados a José como Armando Freitas Filho e Sebastião Uchoa Leite, esses todos com uma obra bastante andada, alguns dos quais inclusive morrendo no tempo em que a revista era publicada, aponta para o fato de que não se pode considerar que 
Inimigo Rumor seja uma tendência fechada dentro da poesia contemporânea. Todavia, as "escolhas afectivas" (nome do site de Aníbal Cristobo, tomado a Goethe e talvez mesclado com os afectos deleuzeanos, em que poetas se indicam, e que contém muitos nomes que estão em Inimigo, a começar por ele próprio) estão sempre agindo: não encontramos Sérgio Cohn, diretor de Azougue (de tendência entre o pop de se propor como fanzine e publicar traduções de surrealistas e beats e o próprio caminho para uma casa editorial e um formato mais "livro"), por exemplo, contribuindo com a revista (mas podemos encontrá-lo no blog de Cristobo), nem mesmo Roberto Piva, a quem Azougue rende tanto tributo em seu segundo número. Também não encontramos ali Alexei Bueno (o dito "neoparnasiano") ou Felipe Fortuna.

Além disso, essa inscrição de uma revista como "antologia" pode nos levar a repensar a tradição em que acaba por se inscrever, qual seja, a dos florilégios, das seleções das "melhores flores" que pode remontar a Francisco Adolfo de Varnhagen, Visconde de Porto Seguro, que publicou em 1850 a primeira seleta da poesia brasileira, contendo apenas "poetas mortos": o Florilégio da poesia brasileira. Grande também foi a vocação antológica de nossos modernistas, especialmente de Manuel Bandeira, e não gratuitamente. Outrossim, outra revista, bem diferente do programa cabralino, também se quis antologia, mas da cultura universal: a já citada Anhembi, herdeira de vários cacos do espólio modernista. Vale lembrar que a antologia foi, durante muito tempo, o instrumento do docente de língua e literatura nas salas de aulas, e que até mesmo podemos pensar que o hodierno "livro didático" é uma forma de antologia, ainda que complementada por exercícios e sugestões de atividades. Daí uma possível ligação entre a idéia mesma de antologia e uma "pedagogia" da literatura, um ensinar a ler, alicerçada não só em "o que ler" (nas seleções do que Carlito julga ser a boa poesia), mas quiçá até no "como ler" (nos ensaios e resenhas veiculadas). Nesse sentido, o movimento de publicar, a partir do número 10 , ensaios sobre o conceito de poesia de autores como Jacques Derrida, Luiz Costa Lima e Bernstein parece bastante significativo, ainda que os conceitos de poesia de pós-estruturalistas como Derrida estejam distantes de uma matriz modernista. 
Essa linha dos autores ou temas a que Inimigo Rumor dedica parte de suas edições (há sempre um quê de aleatório que apenas pode ser afilado pela idéia da escolha de Carlito e de seus companheiros de organização das edições em cada número) pode nos revelar outros tantos dados. João Cabral de Melo Neto figura com apenas dois textos em toda a revista, mas o número sete lhe é dedicado, justamente quando de sua morte, marcando ainda assim algum vínculo efemeridal da revista. Entretanto, nenhum texto dele é publicado na ocasião, nem, ao que indicam as estatísticas da base de dados Periodismo literário e cultural, nas edições subseqüentes da revista. Diferente é o caso do homenageado na edição seguinte, que trai toda a ambição de estabelecer uma linhagem cabralina ou de estabelecer qualquer linhagem: Cacaso. Chama a atenção do editor a "cegueira editorial brasileira para a poesia nacional" e a importância de Cacaso na "desrepressão da linguagem e valorização da experiência", traços para uma poética contra a ressurreição do "oficialismo e do academismo". Entretanto, quão efetiva Inimigo Rumor pode ser fora da academia, se, além de tudo, dá bom espaço para a colaboração de críticos acadêmicos em suas páginas (de Telê Porto Ancona Lopez e Antonio Candido a Alcir Pécora e Murilo Marcondes de Moura) e se volta a uma referencialidade para cuja apreciação é necessário ser praticamente um iniciado em literatura? Ou então, leiamos o academismo como uma forma de dicção da própria poesia. Certamente não a forma de Azougue, ou a de Coyote; talvez a forma de Felipe Fortuna, que tão mal fala do centramento da "poesia contemporânea" em si própria, dizendo que os acadêmicos são os próprios poetas em torno de Carlito e acaba isolado?

O número 9 parece prefigurar a transformação da revista em publicação luso-brasileira. A apresentação dá conta de uma Antologia breve da nova poesia portuguesa. Novamente, a vocação antológica. Parte do texto é novamente de Carlito; outra parte é de Valter Hugo Mãe, a quem é confiada a organização da antologia como "correspondente". Mãe não consegue determinar uma linha-mestra na produção portuguesa que antologiza, como nos é vedado a respeito da produção que Carlito seleciona todo o tempo para Inimigo Rumor: fala do "subjetivismo e individualismo" de alguns, da "descrição mais ou menos empírica do cotidiano" de outros; de "percursos surrealizantes", 
na busca de elementos "essenciais" da condição humana na poesia. Já o número 10 apresenta uma grande mostra de poesia feminina em seu editorial; afirma que nada poderia ser melhor dito do que pelo próprio conteúdo da revista. Anuncia que passará a ser binacional a partir do número 11 , e terá mais dois editores-poetas: Osvaldo Manuel Silvestre e Américo António Lindeza Diogo. A Apresentação não-assinada define Inimigo Rumor como um modo de pensar a literatura pela "negatividade afirmativa"; excertos citados dos ensaios dos portugueses dão conta de leitores de poesia que retornam a Adorno ou ao pensamento da relação entre arte e mercado. Não diria que Inimigo Rumor escape ao mercado: talvez escape ao mercado de massas, mas, em sua transformação em espécie de mercadoria de luxo, praticamente livro, não estaria, talvez, fugindo ao elogio que João Cabral fez a Ferreira Gullar?

A própria idéia de arquivo nos impõe de partida uma série de problemas, que podemos explorar com Derrida, o qual, em 1994, proferiu uma série de conferências hoje publicadas sob o título de Mal de arquivo. Poderíamos ligar, de início, o arquivo à preservação da memória, uma vez que é depositário de um armazenamento, de uma impressão. Entretanto, seguindo o raciocínio do mesmo (?) Derrida quando este lê o Fedro n'A farmácia de Platão, a escrita (e talvez por extensão possamos pensar o arquivo) é remédio e veneno da memória, uma vez que, ao tempo em que a salvaguarda, a registra, a imprime, também a hipoativa enquanto registro mental humano do passado (do presente, do futuro, se pensarmos com Virno). Arquivar a poesia do presente, recuperar poemas do passado, traduzir e publicar seleções de textos, como faz Inimigo Rumor, é registro, mas também é apagamento: esquecemos de lembrar porque imprimimos. O arquivo do aparelho psíquico parece se retrair a partir do momento em que o phármakon da escrita, seu remédio e seu veneno, lhe é introduzido.

O arquivo, outrossim, é uma forma de poder: tem um princípio topológico (é um lugar) e um princípio nomológico (porta uma lei). Institui uma arkhê: começo e comando, natureza e lei. Para Derrida (2001, p.12), "o sentido de 'arquivo', seu único sentido, vem para ele do arkhêion grego: inicialmente 
uma casa, um domicílio, um endereço, a residência dos magistrados superiores, os arcontes, aqueles que comandavam." Aos habitantes dessa casa estavam reservados o poder de guardar e o de interpretar os documentos: a hermenêutica mostra-se, assim, também, uma forma de poder. Livremente, poderíamos pensar que Carlito Azevedo é o grande arconte da poesia em Inimigo Rumor, seletor e intérprete da cena do presente e ressuscitador dos textos que considera que deveriam circular, que se inscrevem em seu modo de ver a poesia. Entretanto, vários dos textos que publica não estão diretamente alinhados à sua poética, mas travam com ela algum tipo de relação; afinal, foram escolhidos. Selecionar, recortar e organizar são atos de interpretação que trazem, também, um penhor de futuro (ibid., p.31): Carlito faz um balanço da poesia brasileira e ao mesmo tempo, ao publicar produções em curso, inscreve-as na memória. Mas também apaga: a memória, em seu processo de arquivamento das inscrições, é seletiva, tem um princípio nomológico. Nenhum arquivo é Funes.

Todo arquivo, para Derrida, é "instituidor e conservador", "revolucionário e tradicional" a um só tempo (ibid., p.17). Pensando essa afirmação em relação às revistas, podemos vê-las, a um só tempo, como um ato que institui uma linhagem, ou que consolida e divulga um nome (e os nomes por ele selecionados), e que, a um só tempo, conserva esses nomes. Dirigir ou publicar numa revista torna-se um ato de poder, já que todo arquivo tem "força de lei". Outros traços aproximam o arquivo da revista: "Não há arquivo sem lugar de consignação, sem uma técnica de repetição e sem uma certa exterioridade. Não há arquivo sem exterior." (ibid., p.22) O lugar, para nós, é a página, o espaço dispendiado para publicar algum poema; por que publicar este e não aquele? Por que publicar, por que ainda escrever, por que não renunciar à escrita ou ao arquivamento, como tantos Bartlebys pela história afora? Por que a impressão, por que a tipografia? E que exterioridade, em um panorama tão aberto quanto o de Inimigo Rumor? A pulsão de morte (da arkhé?) habita o próprio arquivo: ele também trabalha para sua própria destruição, tende à sua anulação pela capitalização do que "o arruína ou contesta radicalmente seu poder" (ibid., p.24). Ao mesmo tempo, é função do arquivo "pôr em questão a chegada do futuro" (ibid., p. 48) Haverá porta aberta 
para a entrada de um messias na poesia contemporânea? Ou abandonamos o messianismo e interrompemos a própria noção de futuro pela anacronia? Até que ponto a anacronia pode nos servir de redenção por interromper o imperativo de um tempo que quer se pôr como fluindo cada vez mais rápido em direção a um futuro inevitável? Que futuro armar para cada passado? Que passado arquivar para um futuro desejável? Há futuro para a poesia? Há futuro?

Cabe observar que o que Carlito constrói ao longo de sua poética (mas não necessariamente na eleição dos poetas de sua revista, a qual nunca está isenta das afinidades pessoais, talvez mais do que das literárias) pode ser lido como um anacronismo formal, uma visita diferida ao passado, um retorno dos mortos que recebe uma impressão e se torna memória do presente. Entretanto, na salada geral das relações entre poesia e imagem, a presença dos concretistas fala na revista. Fala Haroldo de Campos, morto em 2003, que abre o primeiro número de Inimigo Rumor com sua Renga em New York, muito distante de sua verve vanguardista e vasculhando os escombros da cidade contemporânea, num dizer talvez tributário de Sousândrade, mas que também se volta para a mais antiga tradição, no caso, da renga, antiga forma literária japonesa, como nota Maria Lucia de Barros Camargo (1999), mas também uma fila, uma procissão de versos altamente metrificados. Ainda que em relação direta com um eleito do paideuma, o que pratica Haroldo nesses versos, a meu ver, pode ser lido como um anacronismo formal, uma sobreposição de tempos e de vozes, uma irrupção na cidade pós-moderna de um dizer ancestral, de um rumor da linguagem, da babel e da poeira cuja inerência a ela as Galáxias assinalam. Diferente, entretanto, é o caso do que ainda insiste em fazer seu irmão, Augusto de Campos, que abre o segundo número da revista com morituro, poema de 1994. Primeiramente, a página preta e os caóticos caracteres em branco, como que de uma tela de computador com interferência, anunciando uma espécie de luto da poesia, ou poesia do luto. Ou da melancolia? Augusto ainda deposita crenças no futuro, onde crê estar, e desconsidera o presente, como se este fosse puro déjà-vu, puro passado: 


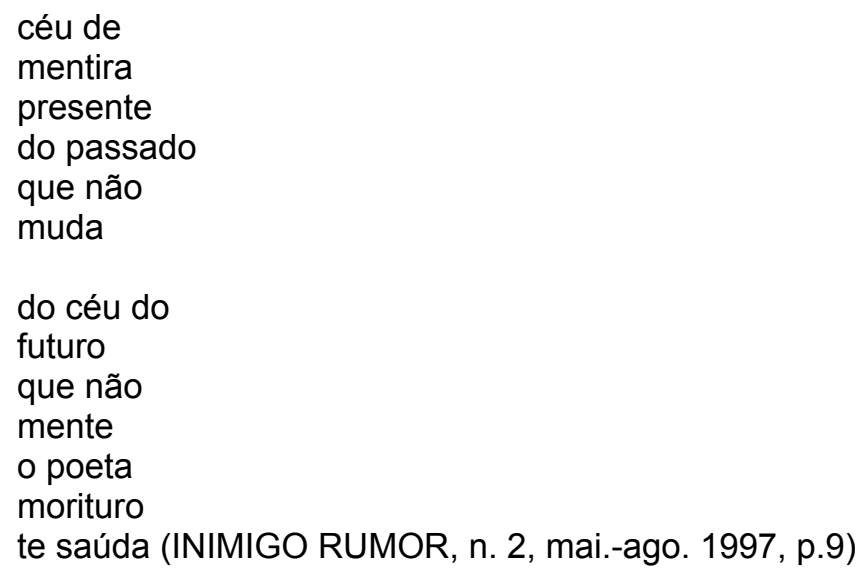

Parece que das palavras do poema podemos arrancar muito do que gostaríamos dizer sobre as noções de tempo e do arquivo que o contém. Negar que o presente possa representar diferença (ou diferimento, dos tempos através dos textos ou dos textos através dos tempos) é afirmar o déjà vu, é fazer exatamente o que poemas como este de Augusto de Campos ainda provocam: sentir o sabor de que alguém em plenos anos 90 (ou 2000) ainda acredita que pode repetir os já exaustos procedimentos de quando era vanguarda, com manifesto, plano e tudo o mais, em meados dos anos 50. A poesia não morreu, ao contrário do que quer Augusto; não considero sequer que se possa dizer que está moribunda, dada a proliferação de publicações, especialmente de revistas, que tem vivido. Sobre a qualidade, o tempo é que a discutirá, ainda que muitos olhem com nostalgia ou para o modernismo, ou para o concretismo, ou para o tempo dos marginais. O que parece ter morrido, definitivamente, é a vanguarda, a idéia de um futuro para o qual haja projeto(jétil) possível. Repeti-la acaba por ser, enfim, criar algo esvaziado de sentido histórico, para retomar o que Virno fala sobre os anacronismos formais. Augusto, deificando a si próprio, pondo-se no céu acima do bem e do mal e do juízo final, é que se torna um anacrônico formal ao parecer não ter ainda se dado conta disso. Um contraponto a Augusto? João Cabral, na resenha que Júlio Castañon Guimarães faz de Poesia é risco / risco é poesia (INIMIGO RUMOR, n. 1, p.103-108), gravação dos poemas do concretista. Seria preferível, ainda, a pretensa unidade verbivocovisual ou uma leitura "sem ênfases, quase monótona", (exausta?) "congenial" à visão que Cabral teria da poesia? Talvez pior do que ver Augusto repetir o que deflagrou na poesia brasileira seja ver um de seus epígonos, Arnaldo Antunes, com brincadeiras do 
tipo "ac asa ala" em letras largas ou um "infinitozinho" ao revés. Sem ser categórico (muito pelo contrário) nos imperativos lineares do tempo, alguém pode avisar que chegamos ao século XXI?

Voltemos, entretanto, às relações entre poesia e imagem, em seu sentido mais direto; no caso, o trabalho gráfico em torno do poema, ou de uma obra que quiçá se faça poema dado seu local de arquivamento, uma revista de poesia. Quiçá uma saída diferida do Concretismo esteja em outro poeta de Inimigo Rumor, cujo trabalho acaba por se tornar singular: Zuca Sardhan. O poeta teria sido amplamente divulgado por Francisco Alvim, colaborador dos mais assíduos da revista de Carlito Azevedo, ligado a boa parte dos marginais (especialmente a Cacaso, cuja presença já não soa mais tão estranha). No número 3 da revista, a profanação se dá em relação às cartas de tarot, símbolos místicos tão respeitados e auráticos, atadas a Baudelaire, por exemplo ("mon coeur mis a nu"), mas temperadas por um sarcasmo ácido para com o próprio lugar de produção, que tudo devora e devolve de maneira enigmática. Quais os caprichos da arte? Talvez, como resposta, somente a roleta do acaso. Temos, ainda, os "medalhões" ou "efígies" que publica no número 7 de Inimigo Rumor, de agosto-dezembro de 1999. A visita às ruínas de Nápoles em algo como um macarrônico, ou ainda, a mistura de Tiepolo com Pasquale (Cipro Neto?) mesclada à gagueira, acabam por estabelecer uma relação de sobreposição entre tempos, reforçada pelo desenho das efígies. As raias do absurdo alertam para o não-sentido que habita toda a linguagem, como no caso do elefante do papa que baila um paso doble na Capela Sistina, e que, O tempora, implode a razão a partir de dentro dela. A sensação, quiçá, seja a do estupor. No arquivo, rumoreja a linguagem.

Chega-me às mãos através de Manoel Ricardo de Lima (um dos membros do atual corpo editorial de Inimigo Rumor), enquanto escrevia este ensaio, um texto publicado no caderno Idéias \& Livros do Jornal do Brasil em 19 de janeiro de 2008, assinado por Felipe Fortuna e intitulado Poesia Brasileira Ltda. Uma ambigüidade já se impõe no título: a poesia brasileira está limitada? Ou transformou-se em empresa, em corporação? Essa primeira crítica se atém à revista recentemente lançada por Marília Garcia, participante 
de Inimigo Rumor e esposa de Carlito Azevedo, Modo de Usar \& Co., juntamente com Fabiano Calixto, Angélica Freitas e Ricardo Domeneck, atacada a partir de sua opção por usar a abreviatura em inglês e da idéia de acionar um novo clima na poesia brasileira. Quiçá, de fato, esse clima não seja tão novo, dado que os poetas que Marília reúne são basicamente os que já vêm de Inimigo Rumor e alguns outros estreantes. O tom de implicância, entretanto, com o programa da revista, estende-se para a idéia de lançar outra luz possível sobre o que parece natural (creio que a linguagem, em si). Além disso, Marília parece querer estabelecer um pacto semelhante ao que Carlito vem fazendo com Inimigo Rumor, pois sua revista quer unir novos poetas recentes brasileiros a nomes da década anterior e à republicação de vozes já mortas que, a seu ver, se mostrem necessárias na cena contemporânea. É um pouco do que tem habitado a maior parte das revistas contemporâneas, mas por que a mordacidade de Fortuna (2008) ao dizer que a proposta é "ideal para formar a equipe de colaboradores de uma revista espírita: convidar poetas que ainda não nasceram para se juntarem aos que já se encontram no além"? Creio que sua crítica à "endogamia" existente na cena poética contemporânea se deva, em boa parte, ao estar de fora. Temos um clube de poetas fazendo a cena atual? Talvez tenhamos mais de um clube, dado que o trânsito entre publicações tão diversas quanto Azougue, Oroboro, Coyote, Cacto, Sibila e Inimigo Rumor, por exemplo, não é completo, ainda que vários nomes apareçam em mais de uma delas. Sua crítica recai inclusive sobre o próprio site de Aníbal Cristobo, As escolhas afectivas, que acaba por interligar novamente os nomes de Carlito, Marília, Cristobo, Fabiano Calixto, entre outros tantos que figuram em Inimigo Rumor, Cacto e Modo de Usar \& Co. Valendo-se da teoria do homem cordial de Sérgio Buarque de Holanda, Fortuna quer se posicionar contra as conexões entre poetas e resenhistas, ou mesmo a existência de um grupo, sobre a qual, creio, não é seguro falar ainda, dada a diversidade da cena e a maneira como esta se encontra intrincada. Refuta, ainda, a metarreferencialidade da poesia, que estaria contribuindo para a queda desta. Trata-se, pois, de um ponto crítico; entretanto, se chegamos a um ponto no debate contemporâneo em que as fronteiras entre a ficção e a dita "realidade" estão abolidas, se essa grande crise da transparência da linguagem 
se impõe sobre a literatura, se a formação humanística do indivíduo tende cada dia mais a ser abolida pelos imperativos da era tecnológica, qual seria a saída desse ser em crise que é a arte senão voltar-se para si mesma? Ou então: será realmente essa outra forma do mal de arquivo da arte a responsável por sua perda de prestígio? Creio que o arquivo em si não é o mal, até mesmo porque as citações sobre as quais Fortuna se debruça para atacar a qualidade da poesia contemporânea nada têm desses anacronismos, como o poema de Fabiano Calixto, dito "prosaico" (talvez mais pelo tema do que pelo tom), tratando da cena política atual, ou uma "tradução" de música de John Lennon e Paul McCartney. Ainda que seja interessante o respeito que Fortuna mantém por Manoel Ricardo de Lima, manifesto ao fim do texto, ou mesmo pelo fato de que Carlito Azevedo consegue congregar tendências poéticas vindas de campos muito diferentes (o que quiçá possa ser um serviço à própria poesia, para além das querelas estilísticas), como afirma em entrevista a Adriano Espíndola (2008), seu tom tende, antes de tudo, a dar conta de uma espécie de despeito de estar por fora desse(s) arquivos.

Talvez a resposta para pensar a poesia contemporânea tenha sido dada muito antes, em Inimigo Rumor número 4. Não há negar, produzem-se maus poemas, Maria Rita Kehl está aí para dar o exemplo, ou até mesmo Fabiano Calixto com o Animal boy, alvo do furor de Fortuna. Ao resenhar Nothing the sun could not explain, antologia organizada por Michel Palmer, Régis Bonvicino e Nelson Ascher e publicada em Los Angeles, Raúl Antelo reflete sobre um conceito negativo de experiência, ao qual chama pós-eventural, a partir do Nada, esta espuma, poema de Ana Cristina César desentranhado de um soneto de Mallarmé. O que chama a atenção é a maneira como Antelo aborda a relação entre Ana Cristina e outros poetas e a tradição: ela passa pelo "afrontamento do desejo", uma liberdade em relação à herança, um poema como "sereia". Trata-se, pois, da

potência equívoca da ficção, a transformação do texto em hipótese esquiva e semovente. [...] O poema quer o particular concreto, 'os seios da sereia'. E muda em conseqüência o lugar da poesia, não mais na proa mas na popa. Ou antes, não no último lugar, o que, extremando a análise, inverteria e reinventaria a escatologia cristã mas no penúltimo, na murada. O poeta pós-eventural desdenha 0 limite e opta pelo limiar porque o limite é último ao passo que o limiar, penúltimo. O limiar busca sair dessa série e começar outra. 
Aspira à continuidade deslocada. O limite, porém, condensa totalidade e reincide no mesmo lugar. (INIMIGO RUMOR, n. 4, p.92)

Trata-se, quiçá, de uma das formas do anacronismo, rediviva, a formal. Esse deslocamento que interrompe a idéia da continuidade, ou, nos termos em que Antelo segue explicitando, essa experiência que é da ordem da exaustão e não do cansaço, percebe o nada do real e não mais caminha para atingi-lo, nega a comunicação e aceita a pungência, o toque, a laceração; potencializase a vontade de chegar a um saber arrancado à morte, ao perigo de estar implicado no jogo que é experiência na linguagem. Essa experiência não é acumulável, não é capitalizável, "assinala o vazio, a impossibilidade de qualquer relação, na forma de um segredo ou ruptura, com algum interior." (ibid., p. 93) E quedam assim todos os traços estabelecidos: sem fora, sem transcendência, inconfrontáveis e petrificantes, os poetas, na pósmodernidade, insistem na escritura, pelo desejo. O rumor do inimigo é mais e mais iminente: entretanto, ele nos habita, estremece, petrifica, mas faz gozar. Poucos são, entretanto, os capazes de encontrar o ponto da abjeção, o paraalém de todos os limites, o desejo que porta em si a mais perversa e deliciosa pulsão da morte, quiçá da morte da própria escrita, da morte do próprio arquivo, ou, à Blanchot (1984, p. 205), o silêncio, o desaparecimento, fim da própria literatura. 


\section{REFERÊNCIAS}

ADORNO, Theodor; HORKHEIMER, Max. Dialética do esclarecimento. Trad. Guido A. de Almeida. Rio de Janeiro: Jorge Zahar, 1985.

AGAMBEN, Giorgio. O cinema de Guy Debord. Trad. Antonio Carlos Santos. Conferência proferida em Genève, em novembro de 1995

. O fim do poema. Trad. Sérgio Alcides. Cacto. N. ${ }^{01}$. São Paulo: Alpharrabio, 2002.

. Profanações. Trad. Selvino Assmann. São Paulo: Boitempo, 2007.

AGUIAR, Melânia Silva de; LOBO, Suely M. P. e Silva. Ler um poema: poesia e pintura em Carlito Azevedo. Disponível em: $<$ http://www.ich.pucminas.br/posletras/Producao\%20 docente/Melania/Carlito\%20Azevedo\%20texto\%20leitura\%20-\%20Suely\%20\%20Melania.pdf>. Acesso em 14 jan. 2008.

AZEVEDO, Carlito. Sublunar. Rio de Janeiro: 7Letras, 2001.

BARTHES, Roland. A câmara clara. Trad. Júlio Castañon Guimarães. Rio de Janeiro: Nova Fronteira, 1984.

. O rumor da língua. Trad. de António Gonçalves. Colecção Signos. Lisboa: Edições 70, 1987.

BENJAMIN, Walter. Obras escolhidas l: Magia e técnica, arte e política. Trad. Sérgio Paulo Rouanet; pref. Jeanne Marie Gagnebin. 7. ed. São Paulo: Brasiliense, 1994.

BLANCHOT, Maurice. O livro por vir. Trad. Maria Regina Louro. Lisboa: Relógio D’água, 1984.

BORGES, Jorge Luis. Del rigor en la ciencia. In: . Obras completas. v. 2: 1952-1972. Buenos Aires: Emecé, 1989.

. Kafka y sus precursores. Disponível em: <http://www.galeon.com/ kafka/borges2.htm>. Acesso em 7 jan. 2008.

CAMARGO, Maria Lucia de Barros. Revistas literárias brasileiras e poesia contemporânea. Boletim de Pesquisa NELIC. n. 4. Florianópolis, jul. 1999. Disponível em: <http://www.cce. ufsc.br/ nelic/Boletim_de_Pesquisa4/texto_mlucia.htm>. Acesso em 12 jan. 2008.

CAMPOS, Augusto de; CAMPOS, Haroldo de; PIGNATARI, Décio. Mallarmé. Coleção Signos. Rio de Janeiro: Perspectiva, s/d.

DELEUZE, Gilles. Crítica e clínica. Trad. Peter Pál Pelbart. São Paulo: 34 
Letras, 1997

Diferença e repetição. Trad. Luiz Orlandi e Roberto Machado. Lisboa: Relógio D’Água, 2000.

DERRIDA, Jacques. A escritura e a diferença. Trad. Maria Beatriz Nizza da Silva. São Paulo: Perspectiva, 1971. (Série Debates.)

. Mal de arquivo: uma impressão freudiana. Trad. Claudia de Moraes Rego. Rio de Janeiro: Relume Dumará, 2001. (Série "Conexões".)

A farmácia de Platão. Trad. Rogério da Costa. 3. ed. São Paulo, Iluminuras, 2007.

ELIOT, T. S. Tradição e talento individual. In: . Ensaios. Trad. Ivan Junqueira. São Paulo: Art Editora, s/d, p. 37-48.

FORTUNA, Felipe. Entre o circunstancial e o mítico. Entrevista a Adriano Espíndola. Disponível em: <http://www.revista.agulha.nom.br/entrevistas01.html>. Acesso em 4 fev. 2008.

Poesia Brasileira Ltda. Jornal do Brasil, Caderno Idéias \& Livros. Rio de Janeiro, 19 jan. 2008.

LUKÁCS, Georg. Ensaios sobre literatura. Rio de Janeiro: Civilização Brasileira, 1965.

MILLIET, Sérgio. Dados para a história da poesia moderna (1922-1928). Anhembi. v. I-II, n. 1-5. São Paulo: Anhembi, dez. 1950-abr. 1951.

SANTIAGO, Silviano. Carlos Drummond de Andrade. Série Poetas modernos do Brasil. Petrópolis: Vozes, 1976.

. Entre Marx e Proust. Folhetim. N. 231. São Paulo: Folha de São Paulo, 21 jun. 1981, p.4.

SIMON, lumna Maria; DANTAS, Vinicius. Poesia ruim, sociedade pior. Novos Estudos CEBRAP. n. 12. São Paulo: CEBRAP, jun. 1985.

SIMON, Iumna Maria. Esteticismo e participação: as vanguardas poéticas no contexto brasileiro (1954-1969). Novos Estudos CEBRAP. n. 26. São Paulo: CEBRAP, mar. 1990.

VIRNO, Paolo. El recuerdo del presente: ensayo sobre el tiempo histórico. Trad. esp. de Eduardo Sadier. Buenos Aires: Paidós, 2003. 